\title{
Metal(II) Complexes of 1,2,5-Oxadiazole
}

\author{
W. L. Driessen and P. L. A. Everstijn \\ Department of Coordination Chemistry, Gorlaeus Laboratories of the State University of Leiden, \\ P. O. Box 9502, 2300 RA Leiden, The Netherlands \\ Z. Naturforsch. 33b, II20-1123 (1978); received June 12, 1978
}

Transition Metal Ions, 1,2,5-Oxadiazole, Ligand Field Spectra, IR

A series of new coordination compounds is reported with 1,2,5-oxadiazole (ODZ) as the ligand, viz. $\left[\mathbf{M}(\mathrm{ODZ})_{3}\right]\left(\mathrm{SbCl}_{6}\right)_{2}$ with $\mathbf{M}=\mathbf{M g}(\mathrm{II}), \mathbf{M n}(\mathrm{II}), \mathbf{F e}(\mathrm{II}), \mathrm{Co}(\mathrm{II}), \mathrm{Ni}(\mathrm{II})$, and $\mathrm{Zn}$ (II). The metal ions are in a regular octahedral environment of six nitrogen atoms. The ligands function as bidentate bridges between the metal ions.

\section{Introduction}

Many heterocyclic ring systems like pyrazole, triazole and isoxazole [1-3] are known to form complexes with various metal ions. Bonding of these ligands to the metal ions occurs through the lone electron pair on the nitrogen atom(s). In our report on the metal(II) solvates of isoxazole [3] we mentioned the occurrence of a high spin-low spin crossover in the iron compound, which appeared to be unique in the sense that this was the first example of such a compound with the iron ions in a regular octahedral environment of monofunctional ligands. In view of the similarity of 1,2,5-oxadiazole to isoxazole we hoped to encounter the same phenomenon with the iron complexes of 1,2,5-oxadiazole. This paper describes the attempts to prepare metal(II) oxadiazole solvates. Hitherto no coordination compounds of 1,2,5-oxadiazole have been reported.

\section{Experimental}

Nitromethane was commercially available and was used without purification after storage over anhydrous calcium sulfate. The ligand, 1,2,5-oxadiazole, was synthesized according to the method described by Olofson and Michelman [4]. The complexes were prepared by adding oxadiazole to a solution of $\left[\mathrm{M}\left(\mathrm{CH}_{3} \mathrm{NO}_{2}\right)_{6}\right]\left(\mathrm{SbCl}_{5}\right)$ in nitromethane [5]. The oxadiazole to metal(II) ratio was varied from $3: 1$ to $8: 1$, but in all cases complexes with an oxadiazole to metal(II) ratio of $3: 1$ were obtained. Even recrystallizing of one of the complexes from pure oxadiazole did not result in a complex with a higher ligand to metal ratio. In all cases clear solutions of the complexes in nitromethane resulted. After concentrating the solutions by evaporation of

Requests for reprints should be sent to Dr. W. L. Driessen, Gorlaeus Laboratories, P.O. Box 9502, 2300 RA Leiden, The Netherlands. nitromethane in vacuo, the solutions were stored at $-5{ }^{\circ} \mathrm{C}$ to $-15^{\circ} \mathrm{C}$. After a few hours or days crystalline solids separated, which were collected on glass filters and washed with sodium-dried $n$ pentane. A copper(II) complex could not be isolated. All compounds decompose when in contact with water. All handling operations were therefore carried out in a $\mathrm{P}_{2} \mathrm{O}_{5}$-dried atmosphere. Attempts to prepare $\left[\mathrm{M}(\mathrm{ODZ})_{x}\right]\left(\mathrm{BF}_{4}\right)_{2}$-complexes with the aid of dehydrating agents (triethylorthoformate or acetic acid anhydride) from the corresponding hydrates were not successful.

The metal(II) contents of the compounds were determined complexometrically [6], the antimony $(\mathrm{V})$ contents were determined iodometrically [7], and the chloride contents were determined by the Volhard method [7]. No nitromethane was detectable in the solid compounds by infrared measurements. Diffuse reflectance spectra in the visible and near infrared region were recorded on a Beckman DK-2 spectrophotometer using the standard reflectance attachment. Infrared spectra were recorded on a Perkin-Elmer 580 double beam spectrophotometer $\left(4000-180 \mathrm{~cm}^{-1}\right)$ as Nujol mulls between $\mathrm{CsBr}$ plates and polyethylene plates. X-ray powder diagrams were obtained with a Philips Powder Diffractometer.

\section{Results and Discussion}

In Table I six new coordination compounds of 1,2,5-oxadiazole (ODZ) are listed with colours, melting points, and analytical data. From the stoichiometry and the colours of the compounds, together with the consideration that no examples exist of metal-coordinated $\mathrm{SbCl}_{6}{ }^{-}$, a first indication is gained that the metal ions are hexa-coordinated by the bidentate (and thus bridging) oxadiazole ligands. The non-formation of $\mathrm{M}(\mathrm{ODZ})_{x}\left(\mathrm{BF}_{4}\right)_{2}$ complexes denotes that oxadiazole is a rather weak ligand. Oxadiazole is apparently not capable of expelling the ligands ethanol or acetic acid from the coordination sphere of the metal ion. In the far infrared spectra of all compounds a strong absorp- 
Table I. Complexes of 1,2,5-oxadiazole (ODZ), their analyses (\% weight), melting points $\left({ }^{\circ} \mathrm{C}\right)$, and colours.

\begin{tabular}{|c|c|c|c|c|c|c|c|c|}
\hline & \multicolumn{2}{|c|}{$\begin{array}{l}\text { Metal(II) }[\%] \\
\text { calcd found }\end{array}$} & \multicolumn{2}{|c|}{$\begin{array}{l}\mathrm{Sb}(\mathrm{V})[\%] \\
\text { calcd found }\end{array}$} & \multicolumn{2}{|c|}{$\begin{array}{l}\text { Chloride }[\%] \\
\text { calcd found }\end{array}$} & m.p. $\left[{ }^{\circ} \mathbf{C}\right]$ & Colour \\
\hline $\mathrm{Mg}(\mathrm{ODZ})_{3}\left(\mathrm{SbCl}_{6}\right)_{2}$ & 2.56 & 2.59 & 25.6 & 25.9 & 44.7 & 45.2 & $152 \mathrm{~d}$. & white \\
\hline $\mathrm{Mn}(\mathrm{ODZ})_{3}\left(\mathrm{SbCl}_{6}\right)_{2}$ & 5.69 & 5.60 & 24.8 & 24.8 & 43.3 & 42.9 & $120 \mathrm{~d}$. & white \\
\hline $\mathrm{Fe}(\mathrm{ODZ})_{3}\left(\mathrm{SbCl}_{6}\right)_{2}$ & 5.68 & 5.67 & 24.8 & 24.6 & 43.3 & 42.7 & $63-65$ & yellow \\
\hline $\mathrm{Co}(\mathrm{ODZ})_{3}\left(\mathrm{SbCl}_{6}\right)_{2}$ & 5.96 & 5.89 & 24.8 & 24.8 & 43.2 & 43.0 & $136 \mathrm{~d}$. & pink-red \\
\hline $\mathrm{Ni}(\mathrm{ODZ})_{3}\left(\mathrm{SbCl}_{6}\right)_{2}$ & 5.96 & 5.87 & 24.8 & 24.4 & 43.2 & 42.8 & $162 \mathrm{~d}$. & blue \\
\hline $\mathrm{Zn}(\mathrm{ODZ})_{3}\left(\mathrm{SbCl}_{6}\right)_{2}$ & 6.59 & 6.65 & 24.5 & 24.9 & 42.9 & 43.2 & $89-91$ & white \\
\hline
\end{tabular}

d. = decomposes.

tion band is present at about $345 \mathrm{~cm}^{-1}$ (see Table II). This band is due to the $v_{3}\left(\mathrm{~T}_{1 \mathrm{u}}\right)$ mode of the octahedral ion $\left(\mathrm{SbCl}_{6}\right)^{-}[8,9]$. Participation of the $\left(\mathrm{SbCl}_{6}\right)^{-}$anion in the coordination of the metal ions can be ruled out, as in that case the symmetry of the hexachloroantimonate $(V)$ ion would have been lowered from octahedral to tetragonal or trigonal, which would at least have resulted in a splitting of the band at $345 \mathrm{~cm}^{-1}$.

The infrared spectra of the complexes all show the same pattern of bands and relative intensities. This means that the solid compounds are largely isomorphous. That isomorphism exists within this series of compounds is shown by the X-ray measurements. The diffraction patterns being very similar in d-values and intensities. Compared to the infrared spectrum of oxadiazole itself, in the spectra of the complexes no splitting of bands occurs and no bands appear or disappear. From these observations it can be concluded that the symmetry $\left(\mathrm{C}_{2_{v}}\right)$ of the ligand is retained in the complexes, which implies that - assuming $\mathrm{N}$-coordination - oxadiazole is present in the complexes as a bidentate bridging ligand. In Table II some of the infrared absorption bands of oxadiazole and its complexes are given. The assignment of the ligand vibrations is after
Borello et al. [10]. The absorption bands of oxadiazole which are due to vibration modes of the heterocyclic ring all shift upon complexing to higher wave numbers. The magnitudes of the shifts lie in the order $\mathrm{Mn}<\mathrm{Fe}<\mathrm{Co}<\mathrm{Ni}>\mathrm{Zn}$. This sequence is in accordance with the general order of stability found by Irving and Williams [11, 12] for this kind of compounds, and which can be regarded as an electronegativity series. The magnitudes of the shifts of the corresponding vibrations in the $\mathrm{Mg}$ compound are comparable to the magnitudes of the shifts in the $\mathrm{Fe}$ or Co compound, which is normal when ligand vibrations are shifted - metal dependent - to higher wave numbers [13]. This behavior can be understood by realizing that the donor atoms are part of the ring system of the ligands. The inductive effect of the metal ions on these donor atoms affects the force constants of the ring vibration modes, thus producing an Irving-Williams sequence of shift magnitudes. The band at $1178 \mathrm{~cm}^{-1}$ of oxadiazole also shows some 'Irving-Williams character', although it is assigned to the in-plane $\mathrm{C}-\mathrm{H}$ bending vibration [10]. This is probably due to coupling of this vibration with ring vibration modes. The out-of-plane $\mathrm{C}-\mathrm{H}$ bending vibration $\left(861 \mathrm{~cm}^{-1}\right)$ does not shift upon complexing. Both

\begin{tabular}{|c|c|c|c|c|c|c|c|}
\hline $\mathrm{ODZ}$ & $\mathbf{M g}$ & $\mathrm{Mn}$ & $\mathrm{Fe}$ & Co & $\mathrm{Ni}$ & $\mathrm{Zn}$ & \\
\hline $1620 \mathrm{vw}$ & $1622 \mathrm{~m}$ & 1624 & 1626 & 1628 & 1630 & 1622 & combination $^{\mathrm{a}}$ \\
\hline $1550 \mathrm{vw}$ & $1555 \mathrm{~m}$ & 1550 & 1556 & 1560 & 1563 & 1557 & combination $^{\mathrm{a}}$ \\
\hline $1314 \mathrm{~s}$ & $1319 \mathrm{~s}$ & 1314 & 1315 & 1324 & 1326 & 1322 & $v_{\text {ring }}{ }^{\mathrm{a}}$ \\
\hline $1178 \mathrm{~m}$ & $1184 \mathrm{~m}$ & 1178 & I182 & 1185 & 1188 & 1185 & $\delta_{\mathrm{C}-\mathrm{H}^{\mathrm{a}}}$ \\
\hline $996 \mathrm{~s}$ & $1005 \mathrm{~s}$ & 998 & 1001 & 1004 & 1008 & 1006 & ring breathing \\
\hline $950 \mathrm{~s}$ & $958 \mathrm{~s}$ & 952 & 953 & 960 & 964 & 961 & $\delta_{\text {ring }}{ }^{\mathrm{a}}$ \\
\hline \multirow[t]{3}{*}{861 vs } & $859 \mathrm{~s}$ & 861 & 861 & 860 & 861 & 860 & $\delta_{\mathrm{C}-\mathrm{H}^{\mathrm{a}}}$ \\
\hline & $424 \mathrm{~m}$ & 408 & 410 & 414 & 419 & 416 & $v_{\mathrm{M}-\mathrm{N}}$ \\
\hline & $345 \mathrm{vs}$ & 344 & 345 & 345 & 345 & 343 & $v_{\mathrm{Sb}-\mathrm{Cl}}$ \\
\hline
\end{tabular}

Table II. Some of the infrared absorption bands $\left(\mathrm{cm}^{-1}\right)$ of 1,2,5-oxadiazole and of the compounds $\left[\mathrm{M}(\mathrm{ODZ})_{3}\right]\left(\mathrm{SbCl}_{6}\right)_{2}$.

a Assignment after ref. [10]; $\mathrm{v}=$ very, $\mathrm{s}=$ strong, $\mathrm{m}=$ medium, $\mathrm{w}=$ weak . 
Table III. Absorption bands (kK) in the visible and near infrared, their assignments, and the calculated ligand field parameters of the iron, cobalt, and nickel 1,2,5-oxadiazole (ODZ) complexes.

\begin{tabular}{|c|c|c|c|c|}
\hline \multirow[b]{2}{*}{$\mathrm{Fe}(\mathrm{ODZ})_{3}\left(\mathrm{SbCl}_{6}\right)_{2}$} & \multirow{2}{*}{$\begin{array}{l}\text { Band maximum } \\
10.5 \quad(11.4-9.2)\end{array}$} & Assignment & \multicolumn{2}{|c|}{ Ligand field parameters } \\
\hline & & $\leftarrow{ }^{5} \mathrm{~T}_{2 \mathrm{~g}}$ & & \\
\hline $\mathrm{Co}(\mathrm{ODZ})_{3}\left(\mathrm{SbCl}_{6}\right)_{2}$ & $\begin{array}{l}9.30 \\
20.6\end{array}$ & $\begin{array}{l}{ }^{4} \mathrm{~T}_{2 \mathrm{~g}} \\
{ }^{4} \mathrm{~T}_{1 \mathrm{~g}}(\mathrm{P}) \leftarrow{ }^{4}^{4} \mathrm{~T}_{1 \mathrm{~g}}(\mathrm{~F}) \\
{ }^{4} \mathrm{~T}_{1 \mathrm{~g}}(\mathrm{~F})\end{array}$ & $\begin{array}{l}\mathrm{Dq}=1015 \mathrm{~cm}^{-1} \\
\mathrm{~B}=830 \mathrm{~cm}^{-1} \\
\mathrm{Dq} / \mathrm{B}=1.22\end{array}$ & $\beta=0.85$ \\
\hline $\mathrm{Ni}(\mathrm{ODZ})_{3}\left(\mathrm{SbCl}_{6}\right)_{2}$ & $\begin{array}{l}10.25 \\
16.7\end{array}$ & $\begin{array}{l}{ }^{3} \mathrm{~T}_{2 \mathrm{~g}} \\
{ }^{3} \mathrm{~T}_{1 \mathrm{~g}}(\mathrm{~F}) \leftarrow{ }^{3} \mathrm{~B}_{2 \mathrm{~g}} \mathrm{~B}_{2 \mathrm{~g}}\end{array}$ & $\begin{array}{l}\mathrm{Dq}=1025 \mathrm{~cm}^{-1} \\
\mathrm{Dq} / \mathrm{B} \leftarrow 1.15 \\
\mathrm{~B}=890 \mathrm{~cm}^{-1}\end{array}$ & $\beta=0.85^{5}$ \\
\hline
\end{tabular}

combination bands (at $1550 \mathrm{~cm}^{-1}$ and at $1620 \mathrm{~cm}^{-1}$ ) also show 'Irving-Williams character'. This is not surprising as these are combination bands of ringvibrations [10]. In the far infrared (between $408 \mathrm{~cm}^{-1}$ and $424 \mathrm{~cm}^{-1}$ ) a band is present which is not due to an anion or ligand vibration. Moreover, the positions of this band follow the Irving-Williams sequence, while the position of this band in the Mg-complex lies highest. This behavior is typical for a metalligand vibration $[3,13,14]$.

The reflectance spectrum of the iron compound in the visible and near infrared shows one asymmetrical band, apparently consisting of two component bands about $2200 \mathrm{~cm}^{-1}$ apart. This might well be caused by a Jahn-Teller splitting of the upper ${ }^{5} \mathrm{E}_{\mathrm{g}}$ level [15]. The reflectance spectra of the cobalt and nickel compounds are typical for octahedral coordination. Accordingly (see Table III), assignments of the bands and calculations of the ligand field parameters were performed $[16,17]$. The values for the spectrochemical parameter $(\mathrm{Dq})$ lie in the range which is normal for nitrogen donor ligands $[3,13,16,17]$. These values are much too high for oxygen coordination $[9,12,16,17]$; and, in addition, it can be remarked that hitherto no examples of similar complexes are known, in which coordination occurs via oxygen atoms which are part of an aromatic system.

Considering that the anion does not participate in the coordination of the metal ions, that the compounds are isomorphous, and that the metal ions are hexa-coordinated, it is clear that oxadiazole functions as a bidentate bridging ligand in our complexes $\left[\mathrm{M}(1,2,5 \text {-oxadiazole })_{3}\right]\left(\mathrm{SbCl}_{6}\right)_{2}$. This means, however, three possibilities for the structure of these compounds. It may consist of linear chains of triply bridged metal ions, or of a three-dimen- sional network of singly bridged metal ions, or of two dimensional sheets of doubly and singly bridged metal ions. On the ground of magnetic measurements a choice between these possibilities could not be made. No evidence for interaction between the paramagnetic ions was obtained by susceptibility measurements down to $1.95 \mathrm{~K}$ and magnetisation measurements at $4.2 \mathrm{~K}$ of the cobalt compound. In connection with the good solubility of the complexes in nitromethane one is tempted to accept the first possibility.

Upon cooling to liquid nitrogen temperatures, the iron compound retains its spin state. So, although the ligand 1,2,5-oxadiazole is similar to the ligand isoxazole, no spin crossover occurs contrary to the isoxazole-iron compounds [3]. This can be understood by noting that the ligand field strength of oxadiazole $\left(\mathrm{Dq}(\mathrm{Co})=1015 \mathrm{~cm}^{-1}\right.$ and $\mathrm{Dq}(\mathrm{Ni})=$ $\left.1025 \mathrm{~cm}^{-1}\right)$ is significantly lower than the ligand field strength of isoxazole $[3]\left(\mathrm{Dq}(\mathrm{Co})=1140 \mathrm{~cm}^{-1}\right.$ and $\left.\mathrm{Dq}(\mathrm{Ni})=1135 \mathrm{~cm}^{-1}\right)$.

\section{Conclusions}

The existence of metal(II) complexes with $1,2,5$ oxadiazole as the ligand has been proved. These complexes can be synthesized quite easily when moisture is thoroughly excluded. The metal ions are in a regular octahedral environment of six nitrogen atoms. Oxadiazole thus acts as a bidentate bridging ligand.

We thank Dr. D. W. Engelfriet for performing and interpreting the magnetic measurements, and Dr. J. G. Haasnoot and Dr. W. L. Groeneveld for their stimulating interest in this study. 
[1] J. Reedijk, Rec. Trav. Chim. Pays-Bas 91, 1373 (1972).

[2] J. G. Haasnoot, G. Vos, and W. L. Groeneveld, Z. Naturforsch. $32 \mathrm{~b}, 1421$ (1977).

[3] W. L. Driessen and P. H. van der Voort, Inorg. Chim. Acta 21, 217 (1977).

[4] R. A. Olofson and J. S. Michelman, J. Org. Chem. 30, 1854 (1965).

[5] W. L. Driessen and W. L. Groeneveld, Rec. Trav. Chim. Pays-Bas 88, 491 (1969).

[6] G. Schwarzenbach, Die komplexometrische Titration, F. Enke Verlag, Stuttgart 1965.

[7] A. Vogel, A textbook of quantitative inorganic analysis, Longmans, London 1964.

[8] I. R. Beattie and M. Webster, J. Chem. Soc. $1963,38$.

[9] M. den Heijer and W. L. Driessen, Inorg. Chim. Acta 26, 227 (1978).
[10] E. Borello, A. Zecchina, and E. Guglielminotti, Gazz. Chim. Ital. 96, 852 (1966).

[11] H. Irving and R. J. P. Williams, J. Chem. Soc. $1953,3192$.

[12] W. L. Driessen and P. L. A. Everstijn, Z. Naturforsch. $32 \mathrm{~b}, 1284$ (1977).

[13] P. L. A. Everstijn, A. P. Zuur, and W. L. Driessen, Inorg. Nucl. Chem. Lett. 12, 277 (1976).

[14] J. Reedijk, Rec. Trav. Chim. Pays-Bas 88, 1451 (1969).

[15] A. D. Liehr and C. J. Ballhausen, Ann. Phys. 3, 304 (1958).

[16] J. Reedijk, W. L. Driessen, and W. L. Groeneveld, Rec. Trav. Chim. Pays-Bas 88, 1095 (1969).

[17] J. Reedijk, P. W. N. M. van Leeuwen, and W. L. Groeneveld, Rec. Trav. Chim. Pays-Bas 87, 129 (1968). 